UNIVERSUM • Vol. $30 \bullet$ No $1 \bullet 2015 \bullet$ Universidad de Talca

La conformación de discurso feminista en diálogo con los discursos sociales: Las mujeres frente a los problemas sociales del 30 Claudia Montero

Pp. 153 a 171

\title{
LA CONFORMACIÓN DE DISCURSO FEMINISTA EN DIÁLOGO CON LOS DISCURSOS SOCIALES: LAS MUJERES FRENTE A LOS PROBLEMAS SOCIALES DEL $30^{1}$
}

\author{
The formation of feminist discourse dialoguing with social discourses: \\ Women faced with social problems in the 30 s
}

Claudia Montero*

\begin{abstract}
RESUMEN
Este trabajo se pregunta por la conformación del discurso feminista en la década del 30 en Chile, momento en que las mujeres se consolidaron como grupo político y legitimaron sus demandas. Se consideran discursos de dos organizaciones: el Partido Cívico Femenino y el MEMCH. El objetivo es analizar cómo se abordaron problemas de la sociedad en un corpus que cubre no sólo textos programáticos, sino de temas generales. Se busca visualizar el diálogo del discurso feminista con otros discursos sociales en una estrategia que permite concluir que las organizaciones consiguieron unidad, para lo que recogieron elementos ajenos a su marco ideológico específico feminista.
\end{abstract}

Palabras clave: Historia de mujeres, Historia de Chile, década del 30, discurso feminista, eugenesia, maternidad, ilegitimidad.

\footnotetext{
${ }^{1}$ Este texto forma parte del proyecto postdoctoral Fondecyt № 3120018, en el marco del Convenio de Desempeño para las Humanidades, Artes y Ciencias Sociales de la Universidad de Valparaíso.

* Instituto de Historia y Geografía, Universidad de Valparaíso. Valparaíso, Chile. Correo electrónico: claudimontero@gmail.com
}

Artículo recibido el 24 de septiembre de 2013. Aceptado el 14 de julio de 2014. 


\begin{abstract}
The question in this peace of work is about the conformation of a feminist discourse in 30's in Chile. That is a key moment because women were consolidated at public sphere and achieve legitimation. The analysis considers the discourse of two feminist organizations: Partido Cívico Femenino and MEMCH. The goal is analyses the approach of social problems in a range of texts, which exceed programmatic ones; in order to visualize a dialogue between feminist discourse and other social discourses. That reveals a strategy which permit conclude that feminist achieved unity, taking element far from their ideological frame.
\end{abstract}

Keywords: History of women, History of Chile, Chile 1930, Feminist discourse, eugenics, motherhood, childhood, illegitimate children.

\title{
INTRODUCCIÓN
}

La década del 30 es un momento clave en la conformación del discurso feminista en Chile. El contexto de crisis económica llevó a una polarización y radicalización política que no fue ajeno a las organizaciones femeninas. Agrupaciones de mujeres y feministas salieron a disputar un lugar en el espacio público, definiendo un período en la historia de mujeres en Chile, denominado "movilización social". En este período se consolidaron como grupo político, lo que marcó una salida definitiva a la calle, cuestión que se reflejó en consecución del voto municipal en 1931 y el sufragio total en la década siguiente $(1949)^{2}$. La ampliación al acceso a educación tanto escolar como profesional, junto al incremento de puestos de trabajo en la burocracia estatal, fue un factor de fortalecimiento de las mujeres de clase media. Esta situación las llevó a entrar en la arena política directamente a través de acciones como la organización de mítines y marchas callejeras, participación en congresos nacionales e internacionales, la integración a redes internacionales por la defensa de derechos, presentación de proyectos de ley por los derechos femeninos, y la publicación de revistas y periódicos que se transformaron en un instrumento de difusión del discurso feminista ${ }^{3}$.

En este contexto surge la pregunta ¿Qué discurso construyeron las feministas? ¿Por qué lograron consolidarse como fuerza política en los 30? ¿Fue un discurso que otorgó unidad a las organizaciones? El objetivo de este trabajo

\footnotetext{
${ }^{2}$ Kirkwood, Julieta. Ser politica en Chile: Los nudos de la sabiduría feminista. Santiago de Chile: Cuarto Propio, (1990): 87-89.

${ }^{3}$ Ver: Lavrin, Asunción. Mujeres, feminismo y cambio social en Argentina, Chile y Uruguay, 18901940, Santiago de Chile: DIBAM, 2005; Gaviola, Edda et. al., Queremos votar en las próximas elecciones. Historia del movimiento sufragista chileno 1913-1952. Santiago de Chile: LOM, 2007.
} 
es analizar el discurso feminista en su diálogo con otros discursos sociales, considerando los problemas de la sociedad como la protección a la maternidad, infancia e ilegitimidad en dos organizaciones de mujeres: el Partido Cívico Femenino y el Movimiento Pro Emancipación de la Mujer Chilena.

En términos teóricos y metodológicos se considera el análisis de discurso, entendiendo que los discursos son los significados que recorren las emisiones orales y escritas y que funcionan como un todo de significación; son objeto de análisis en la medida que están definidos por el contexto, que estructura las propiedades o los atributos de la situación social que los origina. En este trabajo se aborda la revisión de las estrategias discursivas, atendiendo los elementos que conforman la enunciación, ya que en ellas quedan las marcas del sujeto que enuncia en relación al contexto, y se examinan los enunciados, analizando los contenidos a través de los temas, las imágenes y los objetos expuestos en el texto ${ }^{4}$.

A través del análisis de discurso se abordan nuevas dimensiones de textos políticos y programáticos, en este caso sobre temas de problemas sociales, y se observan los mecanismos a través de los cuales el discurso feminista se construyó y logró legitimación de sus demandas. Este es un tema que cobra relevancia frente a las consideraciones que se tienen de los discursos de los grupos políticos, que se suponen limpios o alineados con la ideología que los anima, y sin embargo, están construidos en diálogo con otros discursos sociales. La idea de discurso social considera establecer un sistema en un entramado de discursos en el que se observan puntos de vinculación y conflicto, formaciones ideológicas emergentes, presencia de hegemonía a través de prácticas que homogeneizan o imponen temas, movimientos dados por desestabilizaciones y confrontaciones que pueden ser radicales o superficiales 5 . El discurso feminista al entrar en este diálogo establece acuerdos, desacuerdos o contradicciones, cuestión que termina por fortalecer a las sujetos que los emiten.

En cuanto a la construcción del corpus, este trabajo recoge textos que traducen de forma evidente la propuesta política de las organizaciones como editoriales o artículos de análisis feminista, sin embargo también se incluyen otros textos que en estudios previos no se consideraban a la hora de analizar el discurso feminista en Chile, como aquellos que abordan las temáticas de análisis de problemas sociales generales. Este criterio de selección cobra relevancia en la medida que al no ser exclusivamente textos programáticos o de formación u orgánica institucional, se hace evidente el diálogo con otros discursos sociales, develando una estrategia de consolidación como discurso político.

\footnotetext{
${ }^{4}$ Van Dijk, Teun A. Racismo y discurso de las élites. Barcelona: Gedisa, 2003.

5 Angenot, Marc. "La Historia en un corte sincrónico: Literatura y discurso social". En Interdiscursividades. De hegemonías y disidencias. Córdoba: Editorial Universidad Nacional de Córdoba, (1998): 69-96.
} 


\section{ALGUNOS ELEMENTOS DE CONTEXTO}

La década del 30 junto con la crisis económica, estuvo marcada por intensos cambios políticos, retrocesos en la democracia, radicalización y polarización ${ }^{6}$. Paralelamente el Estado se reorganizó incrementando su burocracia, lo que contribuyó al fortalecimiento de los grupos de clase media ${ }^{7}$. Por su parte, los grupos de mujeres se alzaron con voz propia frente a los conflictos sociales y se unieron en torno a las demandas para mejorar las condiciones sociales y conseguir el voto femenino. La politización social empujó a las mujeres profesionales a reclamar un lugar como personas públicas en tanto trabajadoras de los servicios sociales estatales emergentes, y no sólo como meras beneficiarias de políticas públicas ${ }^{8}$. De tal forma, las organizaciones de mujeres proliferaron, y aunaron sus fuerzas por la defensa de los derechos políticos lo que culminó en 1934 con el reconocimiento del derecho a voto femenino en elecciones municipales.

Dentro de las organizaciones nacionales que desarrollaron un discurso feminista estaban el Partido Cívico Femenino y el MEMCH (Movimiento Pro Emancipación de la Mujer Chilena). Ambas fueron parte de los grupos más influyentes al plantear las demandas femeninas. Si bien la primera se declaraba de izquierda moderada y la segunda radical, la acción conjunta que realizaron ambas organizaciones expresa la necesidad de unidad en la lucha por las demandas de las mujeres. El Partido Cívico Femenino fue uno de los primeros partidos políticos de mujeres en Chile, fundado en 1922. Durante su primera década se definió feminista moderado. Esto significaba que defendía la igualdad de las mujeres en el plano civil y político a través de la demanda por derechos sin cuestionar el orden social. En los años 30 la organización se declaró progresista, girando definitivamente hacia la izquierda y se comprometió con la búsqueda de soluciones a los problemas sociales. Su programa incluyó la revalorización del trabajo femenino, leyes de asistencia social para la clase obrera, profilaxis familiar, investigación de la paternidad y educación sexual? .

Por su parte MEMCH se formó en 1935 con Elena Caffarena y Marta Vergara a la cabeza. Su objetivo era la defensa de los derechos y bienestar de las mujeres, declarándose decididamente feminista e independiente de todo partido político ${ }^{10}$.

\footnotetext{
${ }^{6}$ Para una caracterización de la política del período revisar autores como: Correa, Sofía et al., Historia del siglo XX chileno. Santiago de Chile: Sudamericana, 2001. Drake, Paul. Socialismo y populismo. Chile 1936-1973. Valparaíso: Pontificia Universidad Católica de Valparaíso, 1992.

${ }_{7}$ Un análisis profundo de este proceso en Barr-Melej, Patrick. Reforming Chile. Cultural, Politics, Nacionalism and the Rise of the Middle Class. California: Chapell Hill and London, 2001.

${ }^{8}$ Lavrin, Asunción, op. cit.

${ }^{9}$ Montero, Claudia. "El Problema femenino: Discursos oficiales en la prensa de mujeres, Chile 1920”, CLÍO, Revista de la Facultad de Historia, Nueva Época 33 (2005): 143-158.

${ }^{10}$ Antezana- Pernet, Corinne. El MEMCH hizo historia. Santiago de Chile: Imprenta SEIT, 1997.
} 
Desarrollaron un feminismo radical para su época y terminaron por convertirse en la organización más grande de su tipo, con presencia en todo el país. Fue una organización multiclasista, sin embargo predominaban las mujeres de clase media educada y profesionales; muchas de ellas empleadas públicas, que en el ejercicio de sus labores atestiguaban la precariedad de las condiciones de vida de la población y especialmente de las mujeres ${ }^{11}$.

En la década del 30 se manifestó una crisis del modelo capitalista y los cambios de la modernización alcanzaron su máxima expresión lo que también transformó las relaciones personales e íntimas. Las formas de socialización se alteraron con las nuevas ocupaciones laborales, la migración campo-ciudad, los nuevos espacios urbanos, entre otros fenómenos. A eso se debe sumar la necesidad del Estado de ordenar la sociedad de acuerdo con parámetros que guiaran a Chile por la senda del desarrollo, por lo que se planteó regular o normalizar estas relaciones, lo que significaba imponer el peso de la ley para definir los roles de cada miembro de la familia. De tal forma se discutió la protección de las mujeres y la infancia, la concepción de familia y matrimonio, incluyendo los temas de ilegitimidad y divorcio.

Uno de los discursos que orientó la labor de ordenamiento del Estado fue la eugenesia, que se tradujo en el control y planificación de los hechos vitales de las personas ${ }^{12}$. La eugenesia surgió como ciencia a fin del siglo XIX en Europa, planteando el principio de las leyes de la herencia para el mejoramiento de la raza $^{13}$. La idea era controlar genéticamente las características de la población para propiciar la reproducción de los sujetos considerados aptos para el progreso. A la vez buscaba evitar la degeneración de la raza causada por las enfermedades venéreas y los llamados males sociales. El Estado chileno vio en estos principios la justificación para estimular la reproducción selectiva, propiciando la de sujetos saludables y evitando la que aquellos catalogados como débiles y/o enfermos. La promesa final de la eugenesia era extender la esperanza de vida, traducida en reproducir las mejores condiciones físicas y psíquicas. En Chile la eugenesia cobró fuerza entre 1924 y 1938, y se la vio como la salvadora de la población y su calidad de vida. Los profesionales creyeron encontrar la clave para aumentar el crecimiento demográfico y disminuir los problemas de salud ${ }^{14}$. Con ese objetivo se recogió además el higienismo y se concentraron en el control de la sexualidad a través de reformas sociales y de políticas de salud pública. Un ejemplo de ello fue el decreto

\footnotetext{
${ }^{11}$ Ibid.

${ }^{12}$ Outtes, Joel. "Disciplinando la sociedad a través de la ciudad: El origen del urbanismo en Argentina y Brasil (1894-1945)", EURE 28 (2002): 7-29.

${ }^{13}$ Subercaseaux, Bernardo. "Raza y Nación: El caso de Chile", A Contra Corriente 5/1 (2007): 29-63.

${ }^{14}$ Lavrin, Asunción, op. cit. 150.
} 
ley sobre Defensa de la Raza en 1925 que definía como una labor estatal la lucha contra las enfermedades y las costumbres que las causaban ${ }^{15}$. Si bien la intención de control de los asuntos íntimos de la población generó resistencia, y se cuestionó la capacidad del Estado para restringir las libertades personales, el discurso eugenésico prevaleció en políticas de prevención y educación.

\section{LA DEFENSA DE GRUPOS VULNERABLES: DISCURSOS EN TORNO A LA PROTECCIÓN DE LA MATERNIDAD, LA INFANCIA E HIJOS ILEGÍTIMOS}

Andrea del Campo plantea que en la década del 30, el Estado considerando los principios de la eugenesia, cambió rotundamente el paradigma sobre los asuntos relacionados con la sexualidad. Desde una idea que los establecía como problemas pertenecientes al dominio femenino, asociados a la intimidad dejándolos en una zona oscura, se asumió la sexualidad como un tema de política pública, que se debía exponer y en el que ambos sexos debían asumir responsabilidad. Más aún, en relación con las enfermedades venéreas, se establecía a los hombres como los principales responsables del contagio ${ }^{16}$. Parte de los temas asociados a la sexualidad era la maternidad y como consecuencia hubo una reflexión en torno al rol de las mujeres en tanto madres. Según la eugenesia, las mujeres eran una pieza clave en el desarrollo ya que eran quienes cumplían la función de seleccionar la especie. Frente a ello, tenían una función social como reproductoras lo que justificaba que el Estado se hiciera cargo de la protección de las mujeres. Al respecto Carlos Monckeberg, jefe de la Maternidad del Hospital del Salvador a partir de la década del 20, planteaba que la sabiduría femenina se traducía en ser la conservadora de la pureza de la raza, por lo que:

... toda mujer encinta es respetable y debe ser respetada. La casada, por su sólo título de madre, la soltera, porque a este título agrega la simpatía que emana de su obediencia a la ley natural que la induce a crear la vida ${ }^{17}$.

\footnotetext{
${ }^{15}$ Labarca, Catalina. "Todo lo que usted debe saber sobre las enfermedades venéreas”. En María Soledad Zárate (comp.), Por la Salud del Cuerpo. Historia y politicas sanitarias en Chile. Santiago de Chile: Ediciones Universidad Alberto Hurtado, (2008): 90.

${ }^{16}$ Del Campo, Andrea. "La Nación en peligro: El debate médico sobe el aborto en Chile en la década de 1930”. En María Soledad Zárate (comp.), Por la Salud del Cuerpo. Historia y políticas sanitarias en Chile. Santiago: Ediciones Universidad Alberto Hurtado, (2008): 131-188.

${ }^{17}$ Citado por Labarca, op. cit. 115.
} 
Del Campo plantea que estas ideas se alineaban con el rol tradicional otorgado a las mujeres por la República, reactualizando la labor de las mujeres como "madres de la patria" ahora con el mandato de parir nińos fuertes y aptos. Junto con este discurso, el Estado sumó otro discurso más asociado a las madres obreras. Este último se relacionaba con la protección de los grupos vulnerables dada la crisis económica. Si bien este discurso se venía desarrollando desde el siglo XIX y caracterizaba a las obreras como explotadas físicamente y moralmente víctimas del capitalismo, el discurso Estatal en los 30 fusionó estos planteamientos con la necesidad de potenciar el desarrollo demográfico del país, cuestión necesaria para continuar en la senda del desarrollo económico. En este punto el discurso eugenésico tenía sentido en la medida que propiciaba la reproducción de los sujetos que aseguraran hijos sanos para el trabajo. Esto se tradujo en el Código del Trabajo de 1931 que se propuso resguardarlas del abuso patronal, estableciendo la maternidad como un bien social protegido por ley ${ }^{18}$.

Las obreras, durante el embarazo, tendrán derecho a un descanso que comprenderán seis semanas antes del alumbramiento y seis semanas después. En este período se prohíbe el trabajo de las obreras embarazadas en los establecimientos industriales o comerciales ${ }^{19}$.

Frente a este discurso de protección a la maternidad, el discurso feminista estuvo en acuerdo y aplaudió la legislación que reconocía una demanda levantada por las mujeres en vista de conseguir una sociedad más igualitaria. De tal forma se alinearon con el discurso eugenésico que estaba tras la definición de la maternidad como una función social y la concepción de la niñez como capital humano. Con ello replicaron con fuerza estas ideas como se puede leer en un texto programático de la revista La Mujer Nueva:

Ante todo la maternidad debe ser una función social y el niño, reconocido como capital de la nación, colocado bajo la protección y control del Estado ${ }^{20}$.

Sin embargo el discurso feminista planteó una diferencia, ya que para él la protección de la madre obrera no obedecía exclusivamente a su capacidad de concepción, sino que era necesario reivindicar el trabajo femenino en sí mismo, en tanto otorgaba independencia económica a las mujeres. Esto significaba dar un paso más por lograr una sociedad que eliminara la situación de subordinación

${ }^{18}$ Zárate, María Soledad."Las madres obreras: Identidad social y política estatal, Chile, 1930", Revista de Historia Social y Mentalidades IX/1-2 (2005): 64.

${ }^{19}$ Código del Trabajo, Libro II, Título III, II. Santiago de Chile: Nascimento, (1932): 69.

20 "La maternidad, función social!", La Mujer Nueva, no 6, mayo 1936, Santiago de Chile, 4. 
femenina en Chile. Esta defensa se hizo especialmente potente en momentos de crisis económica, ya que al alterarse los patrones de comportamiento familiares con la cesantía de muchos hombres; las mujeres tuvieron que salir a buscar la mantención del hogar. De tal forma, la emancipación de las mujeres quedaba travestida en una demanda de justicia social frente a la crisis:

Sin lugar a dudas el punto más importante del programa del Movimiento Pro Emancipación de las Mujeres de Chile es el que se refiere a la emancipación económica de la mujer, entendiendo por tal la conquista del derecho a tener asegurado el mínimum que todo ser humano necesita para subsistir, es decir, el pan, el techo y el abrigo ${ }^{21}$.

En América Latina la eugenesia no hacía una diferencia tajante entre "naturaleza" y "crianza", por lo que las condiciones sociales y económicas eran parte del discurso al momento de considerar los factores que explicaban el deterioro de los individuos ${ }^{22}$. La lectura de la situación desmedrada de la población estaba en línea con las ideas socialistas que fueron desarrolladas por los reformadores sociales de los ańos 30. En ese contexto se entiende el texto de Salvador Allende "La realidad Médico-Social Chilena" de 1939 que escribió siendo Ministro de Salubridad del gobierno de Pedro Aguirre Cerda. En él realiza un análisis de la situación de la población en relación con las altas tasas de mortalidad que presentaba el país, y se hace evidente el discurso eugenésico latinoamericano. La inclusión de cuestiones relativas a las condiciones ambientales y materiales hacían que la eugenesia latinoamericana demandara pan, techo y abrigo, como lo proponían las feministas. Esta mirada de la eugenesia se relacionaba con la necesidad de mejoramiento de la calidad de vida. Por ejemplo, al analizar el aumento de la mortalidad infantil Allende va más allá de las explicaciones genéticas y releva las causas sociales, para justificar la protección de la maternidad:

Las causas de este aumento sorprendente [...] deben buscarse en el desmejoramiento grave de las condiciones de vida y la consiguiente mayor miseria fisiológica de los padres. También son factores de considerable importancia, la incorporación creciente de la mujer a las actividades industriales, la mayor explotación de que son víctimas y la protección insuficiente y en muchos casos nula, durante el embarazo ${ }^{23}$.

\footnotetext{
${ }^{21}$ Caffarena, Elena. "Emancipación Económica”, La Mujer Nueva, ańo I, n² 2, diciembre 1935, Santiago de Chile, 3.

${ }^{22}$ Villela Cortés, Fabiola y Linares Salgado, Jorge E. "Eugenesia. Un análisis histórico y una posible propuesta”, Acta Bioethica 17/2 (2011): 189-197.

${ }^{23}$ Allende, Salvador. La Realidad Médico-Social Chilena. Santiago, (1939): 78.
} 
En relación con la necesidad de mejorar los índices de desarrollo y las condiciones de vida de la población, los reformadores sociales veían el trabajo femenino como un problema en la medida que las horas en que las mujeres madres asistían al trabajo se leía que como descuido de la crianza. En este particular punto queda de manifiesta la tensión con el discurso feminista, ya que este último, por una parte demandó protección materna para las trabajadoras ( $\mathrm{y}$ en eso estaba en total acuerdo con el discurso eugenésico de los reformadores sociales), pero a la vez defendió el derecho al trabajo femenino en sí mismo, cuestionado el mandato social que relegaba a las mujeres a la crianza y que provocaba la incomodidad de las autoridades frente a la realidad de la presencia de mujeres en la fuerza laboral del país.

Paralelamente al discurso por la defensa de la maternidad, se desarrolló un discurso a favor de la protección de la infancia, que significó que a partir de 1928 existiera un Decálogo de los Derechos del Niño formulado por el Cuerpo Médico de Chile, y en 1934 se propusieran leyes de protección a la infancia ${ }^{24}$. Este tema fue aglutinador de las organizaciones de mujeres ya que la protección a la niñez se transformó en una de sus demandas, en virtud de que la crianza y los recursos asociados a ello era parte de la existencia femenina. El feminismo levantó la consigna de la protección infantil incluyéndola no sólo dentro de sus programas políticos, sino que asumiéndolo como una cuestión que forma parte constitutiva de las demandas de las mujeres. Así se lee en este artículo de Acción Femenina titulado "El Partido Cívico Femenino y el problema feminista”, en el que se enumeran las demandas de la organización:

La obtención de mejoras en todas la cuestiones relativas a la mujer y el niño; tutela y protección a la infancia; protección a la maternidad, higiene social, luchando contra el alcoholismo, la tuberculosis, los males sociales; contra la pornografía, el juego y las mil obras que interesan directamente a la mujer y al hogar y que puede ser campo fecundo a la actividad del sexo ${ }^{25}$.

El mismo espíritu, encontramos en el programa del $\mathrm{MEMCH}$, quienes declaraban lo siguiente:

Por la dictación de un Código del Niño que contemple todos los aspectos de la defensa de menores como Juzgados, Reformatorios, alimentos, reglas sobre tuición en las que se considere el interés de los menores y no el de los padres y en especial la investigación de la paternidad y la igualdad de los hijos legítimos e ilegítimos ${ }^{26}$.

\footnotetext{
${ }^{24}$ Lavrin, Asunción, op. cit. 159.

25 "El Partido Cívico y el problema feminista", Acción Femenina, no 1, septiembre 1934, Santiago de Chile, pp. 3-4.

26 "Programa del Movimiento Pro Emancipación de las Mujeres", La Mujer Nueva, n 1, noviembre 1935, Santiago de Chile, 3.
} 
La fuerza expresada por las feministas se encontraba también en la declaración de los reformadores sociales al defender la niñez como capital de desarrollo, en un texto editorial del Boletín Médico de la Caja de Seguro Obligatorio, titulado "Reserva Vital":

EL NIÑO ES LA RESERVA VITAL DE LAS CAJAS. Es el único "valor real" digno de una inversión segura y reproductiva. No es un valor cotizable en los centros bursátiles. Es verdad. Pero es el futuro creador de todos los valores bursátiles. Cuanto se haga por la salud del nińo representa, en plazo no lejano, un acrecentamiento de las reservas económicas de las Cajas, y una disminución de los gastos en atenciones "reparativas de la salud de los asegurados. El esfuerzo productor, sistemático, ininterrumpido y eficaz, de un hombre sano, es el más alto rendimiento de intereses que se puede exigir a un capital cualquiera ${ }^{27}$.

No cabe duda que el discurso feminista y el discurso eugenésico desplegado por los reformadores sociales estaban en acuerdo con la necesidad de protección y mejoramiento de las condiciones de vida. Sin embargo, la diferencia entre las mujeres militantes y los profesionales estaba en la consideración de la persona. Mientras la eugenesia hablaba de recursos para el desarrollo del país, las mujeres defendían la vida y al ser humano. Esta perspectiva la adquirían como trabajadoras de servicios públicos, ya sea médico o educativo, lo que las hacía testigos de las situaciones de vulnerabilidad que vivían los niños. La dimensión política de la denuncia por las condiciones de vida de la nińez en Chile, cobra fuerza cuando se apela al propio Estado y su organización: estando en acuerdo que el desarrollo del país y el cuerpo de la nación depende del bienestar de niños y niñas, las feministas dan cuenta de la contradicción del Estado al desproteger a sus ciudadanos y no generar instituciones fiscales con tal propósito:

Es lamentable observar que la vida humana dentro de las organizaciones sociales actuales es un valor que se menosprecia. El factor hombre no interesa a la colectividad, ya que el cuidado y protección de la salud y de la vida ha estado y está entregado en la casi totalidad de los países a la iniciativa privada a la caridad... Y aquí está la falta grande trascendente de la actual protección de la infancia: no existe una organización médico-social de protección infantil que tome al recién nacido y a la madre y los encadene. No hay un sistema que los dirija y salve a esa vida que empieza aún en contra de la voluntad de muchas madres, cuya ignorancia las hace menospreciar o detestar medidas higiénicas, reglas de alimentación y de cuidados indispensables a la vida del hijo que ha de salvarse. Al Estado sólo le interesa que se inscriba el nacimiento de ese nińo. Para eso tiene su Registro Civil

27 "Reserva Vital". Boletín Médico de la Caja de Seguro Obligatorio, no 9 de 1935, Santiago de Chile, 1. 
donde también se inscribirá el fallecimiento antes de cumplir un año de vida y así se lleva recibiendo vidas con una mano y dando "pases para el cementerio" con la otra y en ese juego macabro e inútil se gasta toda una organización burocrática ${ }^{28}$.

El discurso feminista se fortalece en la denuncia de las contradicciones del discurso estatal. La ironía que se utiliza en este texto evidencia la consolidación de las feministas como grupo político. Pone al descubierto un Estado moderno que registra hechos vitales pero que los utiliza para anotar su propia barbarie, al permitir la muerte de esos mismos niños. El feminismo recoge las mismas ideas del Estado en relación con la necesidad de una población fuerte y sana, pero pone el acento en un lugar distinto, que es la vida en sí misma y no como un valor contable para el desarrollo.

Dado este contexto de vulnerabilidad de la vida infantil, la ilegitimidad se transformó en un elemento que fue discutido por los distintos discursos sociales. Por ejemplo, para los profesionales de la salud, los hijos de madres solteras tenían mayor riesgo de enfermedades y muertes, porque sus madres no podían cuidarlos adecuadamente. De hecho, se estableció una correlación directa entre ilegitimidad y sífilis congénita, alcoholismo y mortalidad infantil ${ }^{29}$. Avanzada la década del 30, los reformadores del Frente Popular, aseguraron que la ilegitimidad era un problema multidimensional que abarcaba cuestiones médicas, demográficas y políticas. Según Salvador Allende la ilegitimidad necesariamente se traducía en pobreza, por lo que también hacía a la persona más indefensa a las enfermedades. Como conclusión, Allende postuló que el abandono paterno y la ilegitimidad eran causa de morbilidad y mortalidad infantil, y como consecuencia limitaba el crecimiento de la población, poniendo a Chile en una situación de inferioridad demográfica ${ }^{30}$.

El primer aspecto de este problema es entonces la ilegitimidad que implica deficientes condiciones de resistencia fisiológica ya que son hijos -en su mayor parte- de madres solteras privadas del apoyo económico del padre. La inferioridad vital, de la ilegitimidad se corrobora si estudiamos los nacidos muertos [...] De ahí la preocupación de este Ministerio por el desarrollo de una política de protección a la madre soltera y la normal constitución de las familias de nuestra clase trabajadora, por lo que ella significa para el porvenir de la madre y el niño ${ }^{31}$.

\footnotetext{
${ }^{28}$ Dr. C.A, "Protección de la infancia en nuestro medio social", La Mujer Nueva, nº Julio de 1936, Santiago de Chile, 1.

${ }^{29}$ Lavrin, Asunción, op. cit. 188.

${ }^{30}$ Rosemblatt, Karin. "Por un hogar bien constituido. El Estado y su política familiar en los Frentes Populares”. En Lorena Godoy et al., Disciplina y Desacato. Santiago de Chile: Sur / CEDEM, (1995): 182.

${ }^{31}$ Allende, Salvador, op. cit. 77.
} 
El discurso feminista estaba en acuerdo con este discurso, ya que rescataba la demanda por la protección de las mujeres en el trabajo. La diferencia entre los planteamientos estaba en que mientras el Estado esperaba una familia normalizada donde las mujeres volvieran al hogar, el feminismo defendía el derecho de las mujeres a trabajar, aunque en condiciones de dignidad, seguridad y protección:

La mortalidad infantil está íntimamente ligada a la cuestión de la natalidad ilegítima. Son los pequeñuelos nacidos fuera del hogar los que están más expuestos a la muerte. No sucede sólo en Chile: es una cuestión que ha sido estudiada en todos los países y cuya causa se explica fácilmente. El hijo ilegítimo no tiene padre que vele por él y por la mujer que lo ha dado a luz. Ésta, en la necesidad absoluta de buscar la subsistencia, tiene que trabajar en faenas a veces pesadas y rudas, que no le conceden tiempo ni descanso, para cuidar con esmero a su criatura. Pronto viene a ser una carga terriblemente difícil de llevar. O le abandona en un asilo, o lo manda criar a manos mercenarias, o lo tiene a su lado atendiéndolo sólo cuando el trabajo se lo permite ${ }^{32}$.

En el discurso feminista un hijo ilegítimo no sólo era un niño o niña abandonada, también era una mujer que debía hacerse cargo de él o ella, generando una situación de vulnerabilidad tanto para el infante como para la madre. Para denunciar la situación, apelaron a la socialización de los varones, en tanto construían su masculinidad a partir de su actividad sexual, sin importar las consecuencias. Eso los hacía irresponsables, y una vez más las feministas tomaron elementos del discurso eugenésico para defender los derechos de quienes se veían vulnerados por la sociedad patriarcal, como que el porvenir de la nación dependía de la salud de los nińos la que a su vez requería de la atención de ambos padres:

A los hombres de este Chile despoblado, no les interesa la suerte de los niños, y por ende de la raza. Tal como los guerreros bárbaros bebían el vino de la victoria en los cráneos de sus víctimas, así hay quienes se engalanan con el recuerdo de las madres y de los hijos abandonados ${ }^{33}$.

En la medida que el discurso eugenésico hacía responsables de la sexualidad tanto a hombres como a mujeres, el feminismo encontró justificación para condenar la tradición cultural de una doble moral sexual para hombres y mujeres, y que dejaba a estas últimas en condición de vulnerabilidad. De tal forma apeló al orden legal vigente y reprobó los vacíos legales que impedían la investigación de la

32 "Los hijos del amor que pasa. Mortalidad infantil y natalidad ilegítima", Acción Femenina, no 10, octubre 1935, Santiago de Chile, 22-25.

${ }^{33}$ Ídem. 
paternidad, y que expurgaban de responsabilidades a los padres ${ }^{34}$. En concordancia a esa postura, podemos ver cómo el Partido Cívico Femenino declaraba lo siguiente como punto 8 de su programa:

Investigación de la paternidad del hijo ilegítimo, consiguiendo una ley en que se obligue al padre a mantener y educar ese hijo como si fuera legítimo ${ }^{35}$.

La defensa de los hijos ilegítimos se transformaba en una demanda feminista no sólo porque eran las madres quienes solían cargar con los hijos de acuerdo al mandato social de la maternidad; sino que era un asunto feminista porque el acto de abandonar a los hijos estaba de acuerdo con una moral social que permitía que los hombres no se responsabilizaran por sus actos sexuales. Mientras las mujeres fueran medidas de acuerdo a una vara distinta, cobraba sentido la defensa de una moral para ambos sexos bajo el ideal de que fuera reconocida la igualdad:

Pero faltan otras medicinas además de éstas (las caridades): las preventivas, las que tratan de impedir que el mal aparezca. Y no pueden ser otras que una propaganda tenaz y constante hecha especialmente por las mujeres y las instituciones femeninas, para hacer comprender a los hombres de este país que la especie no entiende de morales diferentes para varón y hembra, y que el pecado que ellos consideran venial, sin importancia y cuyo peso sólo recae en la mujer, viene a ser pagado por entero por el hijo y por la raza. Pero las mujeres de allá se unieron, formaron instituciones fuertes y poderosas, agitaron la opinión pública y han trabajado pacientemente para inculcar en la sociedad normas más elevadas de justicia moral. Para bien de su raza, de la humanidad ${ }^{36}$.

En este texto podemos destacar dos elementos, por una parte, se vuelve a tomar un elemento eugenésico como es ligar las consecuencias de la ilegitimidad con un posible deterioro de la raza. Con ello se acusa al orden social que es, a la vez, el principal ejecutor del discurso eugenésico. Es decir se cuestiona al Estado con su propia herramienta de desarrollo. Por otra parte, el feminismo utiliza la defensa por la ilegitimidad como herramienta de acción política, fortaleciendo su discurso recogiendo como ejemplo la experiencia de otras feministas de otros países, que lograron visibilidad y fuerza política con la misma demanda.

\footnotetext{
${ }^{34}$ Lavrin, Asunción, op. cit. 189.

35 "El Partido Cívico y el problema feminista”, Acción Femenina, no 1, septiembre 1934, Santiago de Chile, 3-4.

36 "Los hijos del amor que pasa. Mortalidad infantil y natalidad ilegítima", Acción Femenina, no 10, octubre 1935, Santiago de Chile, 22-25.
} 
La defensa de los hijos ilegítimos, se fortaleció al ligar mortalidad y abandono infantil con una cuestión ética. Los argumentos de los defensores de la infancia, incluían la idea que el derecho a investigar la paternidad era un acto de reparación y protección para los hijos; y para los grupos de mujeres, estas medidas implicaban además un desagravio para las madres abandonadas:

La madre soltera, que fue abandonada en el desamparo y blanco de burlas y mofas por parte de la sociedad dura y egoísta de antaño, ha encontrado ya en el seno de colectividades más humanas y magnánimas, inspiradas en una noble conciencia de solidaridad y reńidas con las durezas y agresividades del individualismo, colectividades que han logrado romper la marańa de tradiciones y convencionalismos en que el pasado aprisiona a las sociedades no progresivas, un ambiente de tolerancia y aún de respeto, teniendo a su alcance todos los recursos que el Estado proporciona al niño, sin investigar su origen, pues tanto legítimos como ilegítimos serán los forjadores de la patria del mañana ${ }^{37}$.

El feminismo para desagraviar a las madres abandonadas, puso a la sociedad chilena en los escalones más bajos de la jerarquía del progreso, ya que las que el discurso oficial consideraba civilizadas, habrían logrado superar las discriminaciones a estas mujeres, haciéndose cargo de ellas y de los hijos. En este último punto, retoman el discurso hegemónico que define a los niños como formadores de la Patria, tensando la idea para incluir a los ilegítimos, considerando el principio de igualdad. Este planteamiento del feminismo se alineó con el discurso socialista en la idea de considerar que todas las madres e hijos tenían los mismos méritos y derechos, y se debía eliminar el estigma de la ilegitimidad.

En cuanto a los hijos legítimos e ilegítimos, la tendencia de las sociedades actuales parece ser la de borrar entre ellos toda diferencia y conceder a unos y a otros todo el amparo que pueden proporcionar el padre, la familia y el Estado. Ya es tiempo de levantar el baldón que pesa sobre los hijos ilegítimos y que menoscaba sus energías y limita su porvenir, cuando no los deja expuestos al abandono, las enfermedades y la muerte prematura ${ }^{38}$.

De tal forma, el discurso de los grupos de mujeres tomó este elemento del crecimiento de la nación y fortalecimiento de la Patria como recurso para defender la protección de la infancia, ya que si los futuros ciudadanos no contaban con las

37 Torres, Cleophas. "Responsabilizar la maternidad", Acción Femenina, no 20, marzo 1937, Santiago de Chile, 3 y 13.

${ }^{38}$ Ídem. 
condiciones para su crecimiento sano, sería el Estado quien debía hacerse cargo del descuido que permitía que los hombres, es decir los actuales ciudadanos, no se responsabilizaran de su prole. De tal forma, el Estado debía contar con sistemas asistenciales por lo que mantener el doble criterio moral que permitía que los hombres engendraran sin responsabilizarse, era un costo para la nación ${ }^{39}$.

El abandono de la mujer y de la prole, legítima o no, es aquí una de las causas más frecuentes de miseria y de dolor. La infeliz quema hasta la última gota de energía de su pobre organismo ante la máquina de coser o ante la tabla de planchar para reunir apenas con qué criar a sus niños - cuando el marido, capaz de ganar un buen salario- busca su arrimo bajo otro alero, por el momento más confortable. La sociedad no se estremece de indignación y de caridad, porque estamos acostumbrados al espectáculo, y los hombres continúan mirando estos problemas con un criterio individualista y donjuanesco... Y sin embargo que ha de ser problema individual, cuando llena las Gotas de Leche de criaturas desamparadas que la sociedad tiene que socorrer ${ }^{40}$.

Posiciones conservadoras rechazaban la investigación parental, y abogaban por la defensa del matrimonio legal como medio para terminar uniones ilegítimas, que consideraban generadores de "desorden e inmoralidad". Sin embargo, las feministas vivieron como un triunfo cuando en 1939 se envió un proyecto de ley para regular la situación de los nińos ilegítimos:

El Ejecutivo ha enviado a las Cámaras un proyecto de ley que se ocupa de la situación de los hijos ilegítimos. Todas las mujeres hemos recibido esta noticia con viva satisfacción. Precisa recordar que Chile es uno de los países donde la familia está más mal constituida. Acto habitual en el hombre tener un hijo y partir para no volver. En la clase obrera fue aceptado esto como algo natural, en la clase media y alta ser hijo ilegítimo era hasta hace poco algo infamante. Los prejuicios se han borrado un tanto, pero quedaba en pie la dudosa situación ante la ley ${ }^{41}$.

En este punto, resulta interesante que se defienda la existencia de este proyecto de ley apelando a la conformación familiar, y que se integre en el discurso feminista la idea de una buena o mala familia. Con estas declaraciones podemos ver que dentro de las negociaciones que realizó el feminismo para legitimarse como discurso, tomó elementos de la sociedad tradicional para fortalecer su propio contradiscurso.

\footnotetext{
${ }^{39}$ Lavrin, Asunción, op. cit. 199.

${ }^{40}$ Labarca, Amanda. "Mujeres Sudamericanas", Acción Femenina, no13, enero 1936, Santiago de Chile, 20-22.

41 "Proyecto de ley hijos ilegítimos", La Mujer Nueva, no 23, julio 1939, Santiago de Chile, 8.
} 


\section{CONCLUSIÓN}

El análisis del discurso feminista en dos grupos chilenos en la década del 30 y su diálogo con otros discursos sociales, nos entrega elementos para comprender cómo se conformó el discurso feminista en el país. Una de las estrategias utilizadas para construir un discurso que otorgara unidad de grupo, fue la defensa de grupos vulnerables, cuya situación se agravó en el contexto de la crisis de la década en estudio. Las feministas organizadas en agrupaciones estables, tuvieron a la mano elementos para fortalecer un discurso que demandó mejores condiciones de vida para mujeres embarazadas, niños pobres y niños ilegítimos, ya que eran observadoras directas de la realidad en su labor de empleadas públicas. La defensa de estos grupos incluyó la utilización de elementos de discursos sociales para justificar su demanda.

Por ejemplo, en la defensa de la maternidad se tomaron elementos del discurso eugenésico como las ideas que planteaban el buen nacer para demandar protección de las madres. Las organizaciones de mujeres defendieron la maternidad como una labor social por lo que el Estado debía hacerse cargo de la protección de todas las mujeres embarazadas no importando de qué clase social fueran. Hasta ese punto hubo acuerdo entre feministas y reformadores sociales, de tal forma que el Estado se hizo cargo de esta demanda con una legislación adecuada, aunque centrada en las mujeres de clase obrera sin considerar a las de clase media. Esto significó que el Estado y los reformadores sociales, a partir de un discurso eugenésico característico de América Latina, propiciaron unas ideas en torno a las mujeres como un engranaje del desarrollo económico en la medida que requerían protección para que reprodujeran hijos sanos, futuros trabajadores de la nación. Si bien el discurso feminista hizo eco de la protección materna, cobró fuerza y trabajó en la consolidación de los grupos de mujeres a través de las diferencias que planteaban con ese discurso social. Por una parte, defendieron la calidad de las mujeres de ser sujetos y no meros objetos de desarrollo, para lo que defendieron el trabajo femenino como fuente de dignidad y emancipación. Junto a ello se fortalecieron develando las contradicciones del propio discurso estatal al no ser capaz de convertirse en práctica.

Por su parte, la defensa de la infancia se transformó en otro de los temas en los que se puede vislumbrar la relación del discurso feminista con otros discursos sociales. El acuerdo, otra vez, estuvo en la necesidad de protección en función del desarrollo económico del país. Sin embargo, el discurso feminista aplicó el criterio de género sexual, conectando la desprotección de la niñez con las mujeres, en la medida que estas eran las que se hacían cargo de los hijos. Como colectivo, las organizaciones femeninas consolidaron una crítica al proceso de modernización del Estado que no daba la talla, ya que mientras invertía en seguridad o instituciones fiscales, dejaba de invertir en la población, la que el mismo Estado había declarado 
como la base del desarrollo. Esta crítica es un ejemplo más de cómo el discurso feminista dialoga con el discurso social utilizando los argumentos del mismo discurso Estatal para criticarlo. El caso de niños y niñas ilegítimas es un ejemplo cómo frente a un problema social generado por una cultura de la diferencia sexual, que afecta directamente a las mujeres (ya que son las que se deben hacer cargo de los niños en soltería), el feminismo tomó partido de los planteamientos de la eugenesia para defender los derechos femeninos. En la medida que la eugenesia ponía la responsabilidad del ejercicio de la sexualidad, tanto en hombres como en mujeres, el feminismo encontró justificación para demandar responsabilidad paternal, certificado prenupcial, entre otros.

Finalmente, en una década en que las organizaciones de mujeres se consolidaron y lograron unificarse en la lucha por los derechos políticos; la construcción de un discurso en torno a problemas sociales fue un factor más de reforzamiento de ese proceso. En tanto estrategia, el diálogo con otros discursos sociales y el contexto de la crisis permitió elegir elementos ajenos a los

fundamentos básicamente feministas, y contradecirlos, resignificarlos o aceptarlos para consolidarse como grupo político.

\section{REFERENCIAS}

Angenot, Marc. "La Historia en un corte sincrónico: Literatura y discurso social", Interdiscursividades. De hegemonías y disidencias. Córdoba: Editorial Universidad Nacional de Córdoba (1998): 69-96.

Antezana- Pernet, Corinne. El MEMCH hizo historia. Santiago de Chile: SEIT, 1997.

Barr-Melej, Patrick. Reforming Chile. Cultural, Politics, Nacionalism and the Rise of the Middle Class. California: Chapell Hill and London, 2001.

Correa, Sofía et al., Historia del siglo XX chileno. Santiago de Chile: Sudamericana, 2001.

Del Campo, Andrea. "La Nación en peligro: El debate médico sobe el aborto en Chile en la década de 1930”. En María Soledad Zárate (comp.), Historia y politicas sanitarias en Chile. Santiago de Chile: Ediciones Universidad Alberto Hurtado (2008): 81-129.

Drake, Paul. Socialismo y populismo. Chile 1936-1973. Valparaíso: Pontificia Universidad Católica de Valparaíso, 1992. 
Gaviola, Edda, et al., Queremos votar en las próximas elecciones. Historia del movimiento sufragista chileno 1913-1952. Santiago de Chile: LOM, 2007.

Kirkwood, Julieta. Ser politica en Chile: Los nudos de la sabiduría feminista. Santiago de Chile: Cuarto Propio, 1990.

Labarca, Catalina. "Todo lo que usted debe saber sobre las enfermedades venéreas". En María Soledad Zárate (comp.), Por la Salud del Cuerpo. Historia y politicas sanitarias en Chile. Santiago de Chile: Ediciones Universidad Alberto Hurtado (2008): 81-129.

Lavrin, Asunción. Mujeres, feminismo y cambio social en Argentina, Chile y Uruguay, 1890-1940. Santiago de Chile: DIBAM, 2005.

Montero, Claudia. "El Problema femenino: Discursos oficiales en la prensa de mujeres, Chile 1920", CLÍO, Revista de la Facultad de Historia, Nueva Época, 33 (2005): 143-158.

Outtes, Joel. "Disciplinando la sociedad a través de la ciudad: El origen del urbanismo en Argentina y Brasil (1894-1945)”, EURE 28 (2002): 7-29.

Rosemblatt, Karin, "Por un hogar bien constituido. El Estado y su política familiar en los Frentes Populares". En Lorena Godoy et al., Disciplina y Desacato. Santiago de Chile: Sur / CEDEM (1995): 181-222.

Subercaseaux, Bernardo. "Raza y Nación: El caso de Chile", A Contra Corriente 5/1 (2007): 29-63.

Van Dijk, Teun. Racismo y discurso de las élites. Barcelona: Gedisa, 2003.

Villela Cortés, Fabiola y Linares Salgado, Jorge. "Eugenesia. Un análisis histórico y una posible propuesta", Acta Bioethica 17/2 (2011):189-197.

Zárate, María Soledad. "Las madres obreras: Identidad social y política estatal, Chile, 1930", Revista de Historia Social y Mentalidades IX/1-2 (2005): 59-83. 


\section{Documentos}

Allende, Salvador. La Realidad Médico-Social Chilena. Santiago, 1939.

Caffarena, Elena. "Emancipación Económica". La Mujer Nueva. Santiago I/2 (1935): 3.

Dr. C.A. "Protección de la infancia en nuestro medio social". La Mujer Nueva. Santiago I/8 (1936): 1.

Gobierno de Chile. Código del Trabajo. Libro II, Título III, II. Santiago: Nascimento, 1932.

Labarca, Amanda. "Mujeres Sudamericanas". Acción Femenina. Santiago V/13 (1936): 20-22.

S/A "El Partido Cívico y el problema feminista". Acción Femenina. Santiago VI/1 (1934): 3-4.

S/A "Programa del Movimiento Pro Emancipación de las Mujeres". La Mujer Nueva. Santiago I/1 (1935): 3.

S/A "Reserva Vital". Boletín Médico de la Caja de Seguro Obligatorio. Santiago 9 (1935): 1 .

S/A. "Los hijos del amor que pasa. Mortalidad infantil y natalidad ilegítima". Acción Femenina. Santiago IV/10 (1935): 22-25.

S/A. "La maternidad, función social". La Mujer Nueva. Santiago I/6 (1936): 4.

S/A. "Proyecto de ley hijos ilegítimos". La Mujer Nueva. Santiago II/23 (1939): 8.

Torres, Cleophas. "Responsabilizar la maternidad". Acción Femenina. Santiago VI/20 (1937): 3 y 13. 